\title{
Training future physicians in the era of genomic medicine: trends in undergraduate medical genetics education
}

\author{
Jevon Plunkett-Rondeau, MD, PhD'1, Katherine Hyland, $\mathrm{PhD}^{2}$ and Shoumita Dasgupta, $\mathrm{PhD}^{3}$
}

Purpose: Advances in genomic technologies are transforming medical practice, necessitating the expertise of genomically-literate physicians. This study examined 2013-2014 trends in genetics curricula in US and Canadian medical schools to ascertain whether and how curricula are keeping pace with this rapid evolution.

Methods: Medical genetics course directors received a 60-item electronic questionnaire covering curriculum design, assessment, remediation of failing grades, and inclusion of specific topics.

Results: The response rate was $74 \%$. Most schools teach the majority of genetics during the first 2 years, with an increase in the number of integrated curricula. Only $26 \%$ reported formal genetics teaching during years 3 and 4, and most respondents felt the amount of time spent on genetics was insufficient preparation for clinical practice.
Most participants are using the Association of Professors of Human and Medical Genetics Core Curriculum ${ }^{1}$ as a guide. Topics recently added include personalized medicine (21\%) and direct-to-consumer testing (18\%), whereas eugenics (17\%), linkage analysis (16\%), and evolutionary genetics (15\%) have been recently eliminated. Remediation strategies were heterogeneous across institutions.

Conclusion: These findings provide an important update on how genetics and genomics is taught at US and Canadian medical schools. Continuous improvement of educational initiatives will aid in producing genomically-literate physicians.

Genet Med advance online publication 12 February 2015

Key Words: clinical genetics; genomic medicine; medical genetics; medical genetics curriculum; undergraduate medical education
Knowledge of the human genome and the influence of genetic mechanisms on human health and disease have grown exponentially in the past decade. Advances in technology have enabled the development of genomic tools that are transforming not only the science of medicine but also the delivery of health care. Genome-wide association studies and next-generation sequencing are already being applied clinically for the molecular characterization of tumors, diagnosis of rare disorders, development of targeted therapies, identification of pharmacogenetic variants, and elucidation of the genetic basis of common diseases. ${ }^{2}$ The role of genetics in medicine is extending beyond rare, single-gene disorders and is beginning to impact many areas of medicine across primary and specialty care.

While there is evidence that genomics is transforming the practice of medicine, whether health-care providers are adequately trained to implement genomic medicine is not as well characterized. The transition to genomic medicine depends not only on research and development but also on establishing new policies, practices, and educational paradigms. ${ }^{3}$ Remarkably, while advances in genomic technologies have provided better diagnostic tools and treatment options for genetic diseases, there is a shortage of board-certified medical geneticists and clinical genetics trainees. ${ }^{4}$ In addition to the need for clinical genetics specialists, elements of clinical genetics will more commonly be integrated into many forms of primary and specialty practice. ${ }^{3,5,6}$ Recent reports indicate that medical students approaching graduation may not have appropriate mastery of critical genetics concepts, ${ }^{7}$ that current physicians do not feel adequately trained in genetics and genomics, ${ }^{8-11}$ and that few primary care providers are comfortable ordering genomic tests or explaining test results to patients. ${ }^{12-16}$ In fact, lack of provider awareness and knowledge of genomic medicine has been reported as a barrier to its implementation. ${ }^{6}$ The need for education around genetics and genomics, particularly when and how to use genetic/genomic testing, extends across continuing medical education programs, residency and medical school levels, and all health-care professions., ${ }^{2,4,8,14,16-18}$

To train future physicians who are prepared to practice medicine in the age of genomics, we need to teach our students the basic principles of genetics and genomic technologies, as well as their application to various areas of medicine. While a number of studies report particular curricular innovations, ${ }^{19-28}$ there are few studies describing overall trends in genetics curricula. In 1981 (ref. 29) and 1988 (ref. 30), 28 and 18\% of US medical schools, respectively, did not even offer a course in human genetics. Much has changed in the interval between these studies and a 2005 study in which Thurston et al (published in 2007 (ref 31)) comprehensively surveyed 112 course directors at US and Canadian medical schools, collecting data on years in which genetics was taught, integrated versus stand-alone course structures, contact hours, types of instructors, formats of teaching, course objectives, and specific topics covered. In 2005 the majority (77\%)

${ }^{1}$ Department of Pediatrics, University of Massachusetts Medical School, Worcester, Massachusetts, USA; ${ }^{2}$ Department of Biochemistry and Biophysics, University of California, San Francisco, School of Medicine, San Francisco, California, USA; ${ }^{3}$ Biomedical Genetics Section, Department of Medicine, Boston University School of Medicine, Boston,

Massachusetts, USA. Correspondence: Shoumita Dasgupta (dasgupta@bu.edu) 
of institutions taught medical genetics in the first year of study, with $47 \%$ incorporating aspects of medical genetics training into the third and fourth years of study. Furthermore, the curricular structures were roughly evenly split between stand-alone courses (46\%) and integrated courses (54\%). In addition, the frequency with which specific topics were taught across institutions was also cataloged. Since 2005, however, the fields of genetics and genomics have made astonishing advances in terms of both scientific developments ${ }^{3}$ and technologies, such as next-generation DNA sequencing, direct-to-consumer personal genome testing, and use of exome sequencing in clinical settings. ${ }^{32,33}$ Parallel to this scientific revolution, education has moved toward learnercentered and competency-based education with an emphasis on active learning. ${ }^{34,35}$ As such, medical genetics education needs to evolve with the changing scientific and educational landscapes.

To encompass both advances in genetics and genomics as well as trends in medical education, the Association of Professors in Human and Medical Genetics (APHMG) updated its medical school core curriculum in genetics, ${ }^{1}$ using the Accreditation Council for Graduate Medical Education competency domain $s^{36}$ as a framework, mapping learning objectives to a set of overarching genetics competencies, and providing a framework of principles that can be incorporated into a wide variety of curricular formats. In this context we sought to examine the current status of medical genetics curricula to determine whether they are following suit with advances in genomic medicine. Ultimately, the goal of this study is to provide guidance to genetics educators who must rise to the challenge of providing appropriate training to future physicians who will need to confidently navigate the brave new world of genomic medicine.

\section{MATERIALS AND METHODS}

\section{Course/curriculum demographics}

For the purposes of assessing the undergraduate medical genetics curricular structure, we identified course directors for 17 of 17 medical schools in Canada and 15 of 36 osteopathic (DO) and 121 of 138 allopathic (MD) medical schools in the United States $(n=153)$. We simultaneously developed a 60 -question questionnaire (see Supplementary Data online for the full survey) with skip logic that solicited information about institutional demographics, curriculum design, curriculum oversight, assessment, remediation, inclusion or exclusion of specific content in the APHMG core curriculum, and institutional support of educational work. The content of the questionnaire both built on the content of the 2005 Thurston survey ${ }^{31}$ and expanded the study to capture more detail on curriculum design, assessment, remediation, coverage of specific content, and course leadership and oversight that was not included in prior research. An updated survey was piloted in 2011-2012, and we collected 39 responses from US and Canadian medical schools. The pilot responses helped to further refine the 2013-2014 survey, which was emailed to the 153 US and Canadian medical genetics course/curricular directors for whom we had contact information, as well as members of the APHMG and the Association of Biochemistry Course Directors.
We analyzed the data using Microsoft Excel 2007 (Microsoft Corp., Redmond, WA). Chi-squared tests using the standard chi-squared formula were used for comparisons of categorical data. $t$ Tests, performed using the $t$ test function in Excel, were used to compare means of continuous data.

\section{RESULTS}

We received a total of 157 responses between September 2013 and May 2014. After excluding incomplete and duplicate responses, and 2 responses that were not from North American medical schools, 112 unique responses remained for analysis (73\% response rate). Once unique responses were identified, participant information was separated from survey responses, which were analyzed anonymously. Participants' institutions included 9 Canadian, 10 US osteopathic, and 93 US allopathic medical schools. To compare our data to those of Thurston et al., ${ }^{31}$ who surveyed US and Canadian medical schools accredited by the Liaison Committee on Medical Education, we report here only data from US and Canadian Liaison Committee on Medical Education-accredited allopathic medical schools (102 of 138 schools; 74\% response rate). Notably, data from osteopathic medical schools follow the same trends reported in this study (data not shown).

Seventy-five participants (74\%) identify themselves as the current or past course/curriculum director or codirector. Characteristics of course directors are listed in Table 1. Genetics content is most often directed by geneticists with $\mathrm{PhD}(n=40$; $39 \%), \operatorname{MD}(n=33 ; 32 \%)$, or genetic counseling degrees $(n=$ 3; $3 \%)$. Course leadership also commonly comes from teams of basic science and clinical experts $(n=23 ; 23 \%)$, a team of clinicians $(n=1 ; 1 \%)$, or experts in other disciplines $(n=23$; 23\%) (Table 1). Most courses or curricula have some formal oversight ( $n=83 ; 81 \%)$. This typically comes from basic science $(n=26 ; 25 \%)$ or integrated curriculum committees $(n=48$; $47 \%)$ or medical education administrators $(n=52 ; 51 \%)$.

Participating institutions had variable class sizes: $0(0 \%)$ had 1-50 students; 23 (23\%), 50-100 students; 33 (32\%), 100-150 students; 36 (35\%), 150-200 students; and 10 (10\%), >200 students. These courses serve a variety of students sometimes in an interprofessional setting (Table 1), including allopathic/ $\mathrm{MD}(n=97 ; 95 \%)$, medical scientist $\mathrm{MD} / \mathrm{PhD}(n=44 ; 43 \%)$, dental $(n=6 ; 6 \%)$, graduate $/ \mathrm{PhD}(n=5 ; 5 \%)$, genetic counseling $(n=5 ; 5 \%)$, medical residents/fellows $(n=4 ; 4 \%)$, public health/MPH $(n=2 ; 2 \%)$, and preprofessional $(n=2 ; 2 \%)$ students, as well as other categories of students such as graduate/ MS $(n=2 ; 2 \%)$ and physical therapy/DPT $(n=1 ; 1 \%)$ students. Students likely differ in their preparation for genetics courses, given the variable prerequisites across institutions. Most schools require general biology $(n=69 ; 68 \%)$, whereas a smaller number require or recommend specific biological sciences courses such as genetics $(n=4 ; 4 \%)$, cellular biology $(n=9 ; 9 \%)$, molecular biology $(n=5 ; 5 \%)$, or biochemistry $(n=22 ; 22 \%)$. Statistical courses $(n=11 ; 11 \%)$ and courses in physical sciences, including 
Table 1 Course director and learner characteristics of medical genetics courses taught in US and Canadian medical schools, 2013-2014

\begin{tabular}{lc} 
Course director and learner characteristics & $\begin{array}{c}\text { Respondents, } \\
\boldsymbol{n}(\%)\end{array}$ \\
\hline Expertise of course/curriculum director ${ }^{\mathrm{a}}$ & \\
Geneticist with PhD & $40(39)$ \\
Geneticist with MD & $33(32)$ \\
Basic and clinical sciences team & $23(23)$ \\
Expert in other (nongenetics) discipline & $23(23)$ \\
Genetic counselor & $3(3)$ \\
Clinical sciences team & $1(1)$ \\
Students participating in genetics course/curriculum ${ }^{\mathrm{a}}$ & \\
MD & $97(95)$ \\
MD/PhD & $44(43)$ \\
Dental & $6(6)$ \\
Graduate/PhD & $5(5)$ \\
Genetic counseling & $5(5)$ \\
Medical residents/fellows & $4(4)$ \\
Public health/MPH & $2(2)$ \\
Preprofessional & $2(2)$ \\
Graduate/MS & $2(2)$ \\
Physical therapy & $1(1)$ \\
Pharmacy & $0(0)$ \\
\hline
\end{tabular}

aRespondents selected all that applied.

chemistry $(n=11 ; 11 \%)$, organic chemistry $(n=12 ; 12 \%)$, and physics $(n=11 ; 11 \%)$, are also frequently required.

Respondents quantified the amount of genetics taught each year during medical school. Most schools taught the majority of genetics content during the first 2 years, 77 (75\%) taught the majority in year $1,8(8 \%)$ in year 2, and $16(16 \%)$ split equally between years 1 and 2 (Table 2). When totaling genetics instruction in each year of study, there is currently a greater predominance of genetic content taught during year $1(n=98$ (96\%) in 2014 compared with $86(77 \%)$ in 2005 (ref. 31); $P=$ $0.01)$. There is also less genetics content taught during years $3-4$; only 27 schools (26\%) report formally teaching genetics during years 3 and 4 (Table 2) compared with 53 schools (47\%) in 2005 (ref. $31 ; P=1.3 \times 10^{-9}$ ). Genetics content taught during the clerkship years is most frequently found in the pediatrics $(n=8 ; 8 \%)$, obstetrics/gynecology $(n=2 ; 2 \%)$, internal medicine $(n=2 ; 2 \%)$, or elective medical genetics $(n=2 ; 2 \%)$ clerkships; however, there is significantly less reported inclusion of genetics in these clerkships than in the 2005 study $^{31}$ : pediatrics clerkship $(n=27 ; 51 \%)$, internal medicine clerkship $(n=6$; $11 \%)$, elective rotations $(n=6 ; 11 \%)$, and other clinical experiences $(n=14 ; 26 \% ; P<0.01)$.

Courses devote variable amounts of curricular time to genetics. The mean number of total contact hours for genetics (including biochemical genetics) is 36 hours (SD: 25 hours; Table 2). Stand-alone and integrated courses contained a
Table 2 General characteristics of medical genetics courses taught in US and Canadian medical schools, 2013-2014

\section{Course/curricular characteristics}

Respondents, $n$ (\%)

\begin{tabular}{lc}
\hline Year of curriculum in which majority of genetics \\
content was taught \\
First & $77(75)$ \\
Second & $8(8)$ \\
Equal split between first and second & $16(16)$ \\
Third & $0(0)$ \\
Fourth & $0(0)$ \\
Medical genetics incorporated into third- and & \\
fourth-year clinical teaching & \\
Yes & $27(26)$ \\
No & $58(57)$ \\
Not sure & $17(17)$ \\
Total time taught in course (hours) & \\
Range & $18-102$ \\
Mean & 36 \\
Type of course & \\
Stand-alone & \\
Integrated & $25(25)$ \\
\end{tabular}

similar average number of hours of genetics $(40(S D=18)$ and 35 ( $\mathrm{SD}=27$ ) hours, respectively; $P=0.19$ ). For schools that teach biochemical genetics separately, there is a mean of 12 hours (SD: 10 hours) devoted to this topic. Overall, many participants feel the amount of time spent on genetics is insufficient for preparation for clinical practice $(n=57 ; 56 \%)$ or licensing exams $(n=21 ; 21 \%)$. The remaining participants feel there is adequate time spent on genetics, and no respondents felt too much time was devoted to this discipline. These findings were similar regardless of the training of the course director; that is, clinical and basic science faculty agreed about the relative need for increased educational opportunities in genetics.

Respondents indicated 25 schools (25\%) still teach genetics as a stand-alone course (Table 2). Notably, this stand-alone course structure is becoming less common when compared with the course structures that were identified in the 2005 study $^{31}$ (25\% in 2014 compared with $46 \%$ in 2005 study; $P=0.004$ ). Integrated course structures seem to be gaining favor over time $(75 \%$ of courses in the 2014 study and 54\% of courses in the 2005 study; $P=0.004)$. Currently, genetics content is typically integrated with other basic science content, such as biochemistry, nutrition, or metabolism $(n=20 ; 20 \%)$ or molecular or cellular biology $(n=$ 18 ; 18\%), whereas other schools integrate across the larger curriculum $(n=16 ; 16 \%)$. A few schools integrate genetics with clinical topics $(n=7 ; 7 \%)$, including neoplasia, pediatrics and reproductive health, and pathology. Metabolic genetics is most often included in the genetics course/curriculum $(n=56 ; 55 \%)$, but it is sometimes taught with other topics. Integrated courses are more commonly led by a course director with expertise in another discipline $(n=24 ; 28 \%)$ or a team of course directors with basic 
science and clinical expertise $(n=22 ; 26 \%)$ compared with standalone courses $(n=6(21 \%)$ and $n=2(7 \%)$, respectively; $P=0.10)$.

Approximately half ( $n=60 ; 59 \%$ ) of the respondents indicated that their institution is currently undergoing a curricular change. Of the schools with curricular changes in progress, most indicate a transition from a traditional structure to an organ system/block structure $(n=19 ; 33 \%)$ or an integrated 4-year curriculum $(n=7$; $12 \%)$. Others indicate changes aimed at increasing active learning methods such as team-based learning $(n=10 ; 16 \%)$.

\section{Specific curricular content with respect to APHMG core curriculum}

The majority of participants $(n=61 ; 60 \%)$ accessed the APHMG medical genetics core curriculum ${ }^{1}$ before the survey. Participants report using this document to guide curriculum content ( $n=47 ; 46 \%)$, evaluate curriculum $(n=47 ; 46 \%)$, incorporate learning objectives $(n=28 ; 27 \%)$, and, to a lesser extent, foster integration $(n=16 ; 16 \%)$ or lobby for instructional time $(n=9 ; 9 \%)$. Other participants plan to use the core
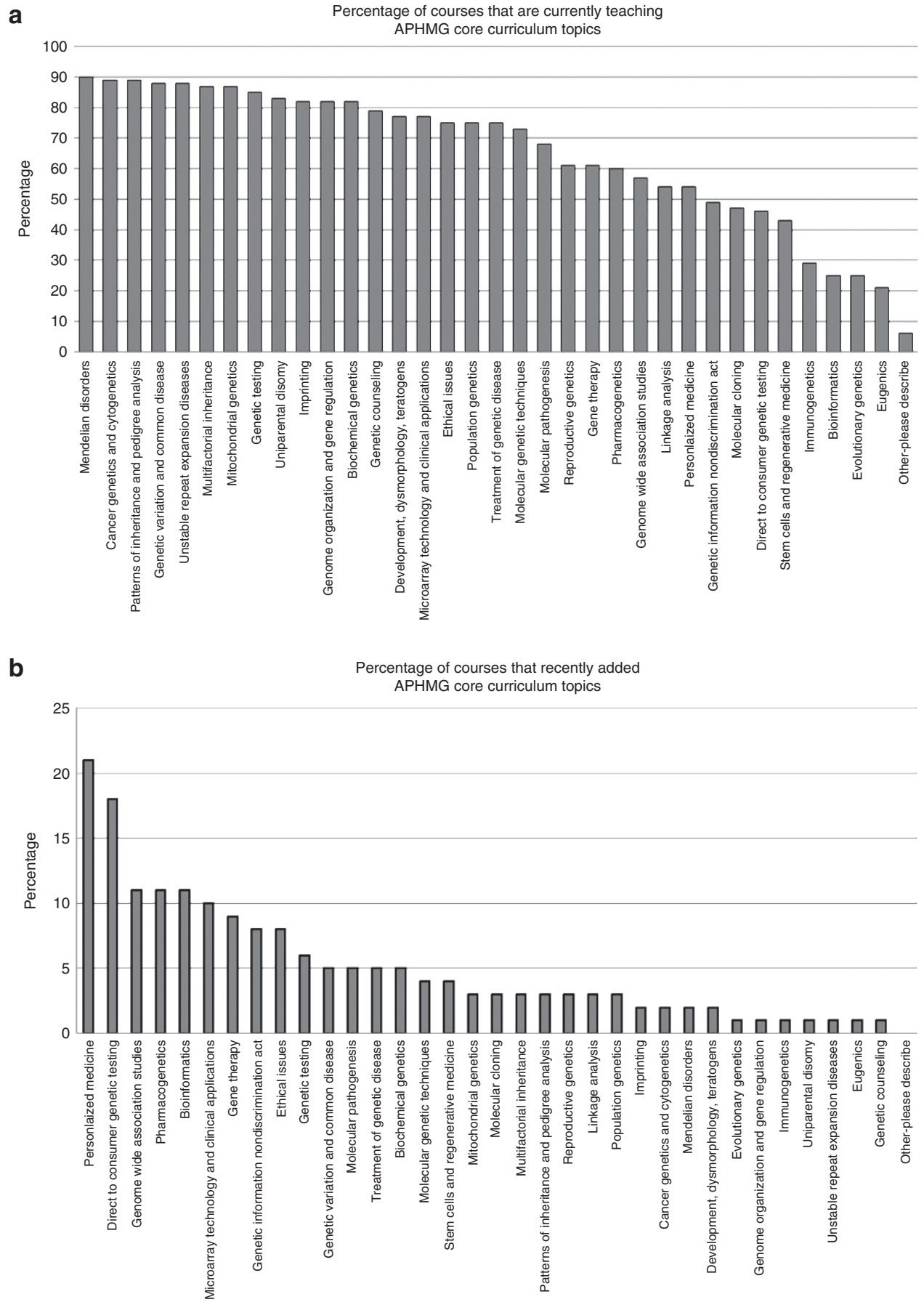

Figure 1 
curriculum in the future $(n=85 ; 83 \%)$ for purposes such as evaluating the adherence of existing curriculum to these guidelines $(n=23 ; 23 \%)$ and/or guiding curriculum content revisions $(n=15 ; 15 \%)$. Participants describe time $(n=7 ; 7 \%)$ and difficulty integrating into existing curriculum $(n=6 ; 6 \%)$ as barriers for using the core curriculum.

To ascertain which of the core curriculum topics were most commonly included in existing courses, we assessed the inclusion of specific topics from the APHMG core curriculum in participating courses/curricula (Figure 1a). Specific topics from the core curriculum that are most consistently covered across participating schools include Mendelian disorders $(n=90$; $90 \%)$, cancer genetics $(n=89 ; 89 \%)$, patterns of inheritance $(n=$ $89 ; 89 \%)$, genetic variation and common disease $(n=88 ; 88 \%)$, unstable repeat expansion diseases $(n=87 ; 87 \%)$, multifactorial inheritance $(n=87 ; 87 \%)$, mitochondrial genetics $(n=87 ; 87 \%)$, and genetic testing $(n=85 ; 85 \%)$. Specific topics most frequently recently added include personalized medicine $(n=21 ; 21 \%)$ and direct-to-consumer testing $(n=18 ; 18 \%)$ (see Figure $1 \mathrm{~b}$ ). Eugenics $(n=17 ; 17 \%)$, linkage analysis $(n=16 ; 16 \%)$, and evolutionary genetics $(n=15 ; 15 \%)$ are the topics most frequently recently eliminated from the curriculum (Figure 1c).

\section{Teaching methods}

Currently, the majority of curricular time is spent in lecture (mean (SD): $56 \%(11 \%)$ ), with considerable time also devoted to small group $(13 \%(15 \%))$ or problem-based sessions $(11 \%$ $(17 \%))$. Patient sessions (8\% (8\%)), team-based learning $(7 \%(11 \%))$, and self-directed or independent learning $(6 \%$ (14\%)) are also commonly used methods. Flipped classroom exercises, where basic content is delivered outside of class and applied during active, in-class exercises (3\% (11\%)), and online learning $(3 \%(11 \%))$ account for smaller but significant portions of teaching time.

Most courses utilize many types of teachers in a course. Lectures most commonly are given by a combination of full-time basic science faculty ( $n=91 ; 89 \%)$, full-time clinical faculty ( $n$ $=82 ; 80 \%)$, and genetic counselors $(n=40 ; 39 \%)$. Small groups are led by a more diverse group: full-time basic science faculty $(n=73 ; 72 \%)$, full-time clinical faculty $(n=70 ; 69 \%)$, part-time faculty $(n=10 ; 10 \%)$, genetic counselors $(n=41 ; 40 \%)$, postdoctoral fellows $(n=12 ; 12 \%)$, graduate students $(n=4 ; 4 \%)$, medical students $(n=11 ; 11 \%)$, or other students $(n=3 ; 3 \%)$.

\section{Assessment and remediation}

In terms of assessment, the major types of both formative and summative assessment still revolve around various forms of multiple-choice questions. In the formative category, however, there was more flexibility with using additional types of assessment (Table 3). Students who do not pass their genetics course or achieve an acceptable level of competency in the discipline may be required to undergo remediation in genetics; they are most frequently asked to take an exam $(n=65 ; 64 \%)$ that is either specifically used for remediation $(n=44 ; 68 \%)$ and/or that is a repeated course exam $(n=24 ; 37 \%)$. Other students are remediated through a course $(n=18 ; 18 \%)$, usually by retaking the genetics course at their home institution $(n=17$; 94\%). A number of institutions create an individualized plan for remediation for each student $(n=46 ; 45 \%)$. Remediation methods for stand-alone versus integrated courses differ in

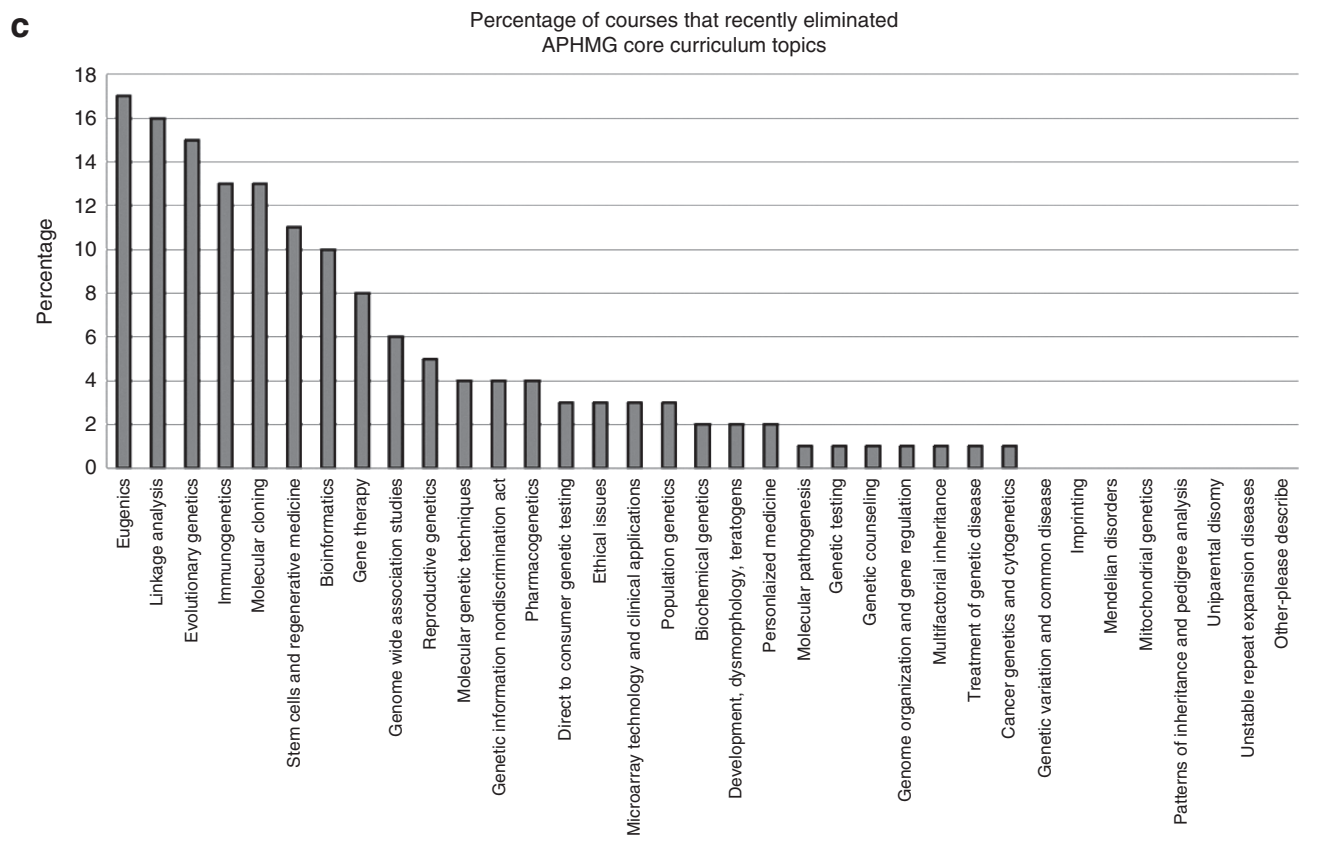

Figure 1 Genetics content in medical genetics curricula. Participants were given the following instruction: "From the following list please select the topics that are included in your medical school's CORE medical genetics curriculum. Select all that apply. A. Currently covered, B. Recently added (within the past 2 years), C. Eliminated." For each case, the $y$-axis shows the percentage of schools that cover (a), recently added (b), or eliminated (c) the topic, and the topics are arranged along the $x$-axis from most to least frequently represented. APHMG, Association of Professors in Human and Medical Genetics. 
Table 3 Teaching and assessment methods of medical genetics courses taught in US and Canadian medical schools, 2013-2014

\begin{tabular}{|c|c|c|}
\hline Characteristics & $\begin{array}{l}\text { Curricular time, } \\
\text { mean \% }\end{array}$ & \\
\hline \multicolumn{3}{|l|}{ Teaching methods ${ }^{a}$} \\
\hline Lecture & 56 & \\
\hline Small group & 13 & \\
\hline Problem-based learning & 11 & \\
\hline Patient sessions & 8 & \\
\hline Team-based learning & 7 & \\
\hline $\begin{array}{l}\text { Self-directed or independent } \\
\text { learning }\end{array}$ & 6 & \\
\hline Flipped classroom exercises & 3 & \\
\hline Online learning & 3 & \\
\hline Assessment methods ${ }^{\mathrm{a}}$ & Formative $^{b}$ & Summative $^{b}$ \\
\hline Multiple-choice questions & $60(59)$ & $87(85)$ \\
\hline Online quizzes & $45(44)$ & $11(11)$ \\
\hline Audience response system & $41(40)$ & $7(7)$ \\
\hline Team-based learning quizzes & $31(30)$ & $16(16)$ \\
\hline Short-answer questions & $20(20)$ & $18(18)$ \\
\hline Writing assignments & $9(9)$ & $8(8)$ \\
\hline Purchased subject exams & $8(8)$ & $21(21)$ \\
\hline Simulated patient encounter & $7(7)$ & $9(9)$ \\
\hline $\begin{array}{l}\text { Observed structured clinical } \\
\text { exam }\end{array}$ & $3(3)$ & $7(7)$ \\
\hline Presentations & $3(3)$ & $0(0)$ \\
\hline Other & $4(4)$ & $0(0)$ \\
\hline None & $0(0)$ & $4(5)$ \\
\hline Remediation methods ${ }^{a}$ & Respondents, $n(\%)$ & \\
\hline Multiple-choice exam & $65(64)$ & \\
\hline Specific to remediation & $44(68)$ & \\
\hline Repeated course exam & $24(37)$ & \\
\hline Course & $18(18)$ & \\
\hline $\begin{array}{l}\text { Repeat genetics course at } \\
\text { home institution }\end{array}$ & $17(94)$ & \\
\hline $\begin{array}{l}\text { Individualized remediation plan } \\
\text { for each student }\end{array}$ & $46(45)$ & \\
\hline None & $5(6)$ & \\
\hline
\end{tabular}

aRespondents selected all that applied.

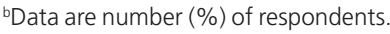

some areas. For example, several integrated courses report lacking any specific assessment $(n=4 ; 5 \%)$ and/or remediation $(n=$ $5 ; 6 \%)$ for genetics topics.

\section{DISCUSSION}

In many primary and specialty disciplines, today's physicians require an increasingly comprehensive understanding of the principles of genetics and genomics to make informed clinical decisions. Scientific discoveries are bringing genomic technologies not only to the clinic but also directly to consumers at an increasingly rapid pace. The availability of genomic information necessitates that educators ensure appropriate coverage of genetics and genomics topics in training future health-care providers. ${ }^{37}$ This study found that genetics curricula are, in fact, evolving to include current topics in genomics. In addition, this study highlights a trend toward using integrated curricular models, as well as diverse and innovative teaching and assessment strategies. Some potentially concerning trends in terms of student accountability for content and expertise of course leadership have also been identified.

The overall trend in curricular format is moving toward integration of genetics with other topics, and many institutions that currently have stand-alone genetics courses are in the processes of transitioning to more integrated formats. Integrated models of instruction certainly have many benefits, including emphasizing application of knowledge to clinically-relevant scenarios. Because genetics and genomics have both foundational science and clinical aspects, this content is perfectly situated to integration with other foundational sciences, as well as across most clinical disciplines.

Medical schools that participated in this survey use a variety of innovative teaching strategies to bring genetics into medical training. Furthermore, curricula have evolved to include topics of particular relevance to the practice of genomic medicine, including personalized medicine, direct-to-consumer genetic testing, genome-wide association studies, pharmacogenetics, and bioinformatics (Figure 1b). When we examine the overall coverage of these emerging topics (Figure 1a), however, we find that over $40 \%$ of respondents still do not cover them in their curricula. To produce genomically-literate physicians, improving the coverage of topics relating to genomic medicine is critical. One way to increase exposure to these topics is to promote more integration of genetics across the 4-year curriculum and highlight existing genetics topics in core clerkships. Our survey results indicate that the majority of genetics content is currently taught in the first 2 years of medical school, with minimal and declining formal instruction in genetics during years 3 and 4. Because the survey respondents were primarily course/curriculum directors of genetics content during the preclerkship phase of training, the numbers we report in our survey may be underestimates of genetics instruction during years 3 and 4; thus surveying clerkship directors in future studies would be helpful. Nevertheless, these results point to an opportunity to extend formal training in genetics across the medical school continuum. Given that many of the instructors currently participating in genetics curricula are clinicians and genetic counselors, there is an opportunity to tap into their expertise to facilitate integration across the 4 years. To assist genetics course and clerkship directors, collaborations across institutions or through professional societies such as the APHMG can be leveraged to develop genomic medicine curricula and share resources. For example, digital technology can be used to reach remote locations or satellite clerkship sites that 
might not otherwise have access to specialists in genomic medicine. On a larger scale, a select number of institutions have been able to implement specialized tracks of study in the area of genomic medicine. ${ }^{23,38}$ Many approaches can be taken to increase student exposure to clinical genetics and genomic medicine during their medical training, and these various approaches can be tailored to fit in an institutionspecific context.

An added benefit of incorporating more clinical genetics and genomics content in medical training, particularly in pediatrics, obstetrics/gynecology, and internal medicine clerkships, is that it may promote medical genetics as a specialty. Although genomic medicine is increasingly a component in clinical care, reports indicate that there is a remarkable shortage of clinical geneticists, and $\sim 50 \%$ of medical genetics residency positions remaining unfilled each year. ${ }^{4}$ While some initiatives to incorporate increased exposure to genetics and genomics during clinical training have been implemented, ${ }^{24,28}$ further development of clinical genetics/genomics curricula is justified given the current trends toward genomic medicine. Another way to enrich our students' exposure to genomic medicine early in their training is through student interest groups in medical genetics. Currently, the ACMG reports ${ }^{39} 17$ medical schools as hosts of medical genetics student interest groups. Expansion of this network would be an excellent mechanism to increase student exposure to this growing field in medicine.

While integration of genetics and genomics with other disciplines has clear benefits, there may be some unintended consequences to consider. With respect to course leadership, we find that a higher percentage of course directors responsible for genetics content are nongeneticists (either MDs or $\mathrm{PhDs}$ ) in integrated curricula than in stand-alone courses. Given the rapid pace of advancement in genetics and genomics, it is increasingly challenging, especially for individuals who are not experts in the field, to provide the breadth and depth of this content necessary for training genomically-literate physicians. In addition, our data suggest that remediation of genetics is not occurring uniformly across all of the participating institutions, with a small number (6\%) of institutions with integrated curricula not requiring any remediation of genetics. This observation may reflect the difficulty of tracking discipline-specific content in an integrated curricular context. Because genetics typically makes up only an average of $2 \%$ of the overall preclerkship contact hours at Association of American Medical Colleges member institutions, ${ }^{40}$ it follows that genetics content may constitute only a small fraction of some integrated examinations. In this case some graduates of medical schools may be able to pass examinations and move forward in their training without meeting basic competencies in medical genetics. There are, however, a number of steps educators and mentors can take to minimize these unintended consequences, including increasing exposure to genetics across all levels of medical training, involving genetics experts in curriculum design and delivery, creating discipline-specific tracking efforts to monitor students' performance on assessments throughout medical training, and offering additional opportunities for students to interact with mentors in the field.

With continued advancements in our understanding of genetic influences on health and disease, physicians' need to interpret genetic and genomic information will likely expand, underscoring the importance for medical school curricula to keep pace with the rapidly evolving field of medical genomics. ${ }^{3,5,6}$ Based on the increasing necessity for health-care providers to be competent in genomics to provide services within their scope of practice, it is both appropriate and necessary for genetics and genomics to be integrated throughout medical school training. As educators, it is our obligation to train the next generation of future physicians to be competent and facile in genetics and genomics so they can translate new technologies and discoveries into clinical practice and usher in the era of genomic medicine.

\section{SUPPLEMENTARY MATERIAL}

Supplementary material is linked to the online version of the paper at http://www.nature.com/gim

\section{ACKNOWLEDGMENTS}

The authors thank the Association of Professors of Human and Medical Genetics for the educational grant ("Undergraduate Medical Education Genetics Curriculum Survey") that supported this work. The authors also thank Jon Bernstein for assistance with survey review and Stanford institutional review board sponsorship and Patricia O'Sullivan for her critical reading of the manuscript. Ethical approval: Institutional review board approval and exempt status were granted by all three host institutions. Dr PlunkettRondeau was pursuing her MD degree at Stanford at the time of the study, and Stanford's institutional review board approved this study under protocol number 28645. On behalf of Dr Hyland, the University of California, San Francisco, Committee on Human Research approved this study under protocol 13-11755. Finally, for Dr Dasgupta, the Boston University School of Medicine Institutional Review Board approved this study under protocol H-32555.

\section{DISCLOSURE}

The authors declare no conflict of interest.

\section{REFERENCES}

1. Hyland K, Dasgupta S, Garber K, et al. Medical School Core Curriculum in Genetics. 2013. Association of Professors of Human and Medical Genetics. http:// media.wix.com/ugd/3a7b87_7064376a9eb346cfa1b85bc2f137c48f.pdf. Accessed 11 December, 2014.

2. McCarthy JJ, McLeod HL, Ginsburg GS. Genomic medicine: a decade of successes, challenges, and opportunities. Sci Transl Med 2013;5:189sr4.

3. Green ED, Guyer MS; National Human Genome Research Institute. Charting a course for genomic medicine from base pairs to bedside. Nature 2011;470: 204-213.

4. Cichon M, Feldman GL. Opportunities to improve recruitment into medical genetics residency programs: survey results of program directors and medical genetics residents. Genet Med 2014;16:413-418.

5. Guttmacher AE, Porteous ME, Mclnerney JD. Educating health-care professionals about genetics and genomics. Nat Rev Genet 2007;8: 151-157.

6. Demmer LA, Waggoner DJ. Professional medical education and genomics. Annu Rev Genomics Hum Genet 2014;15:507-516. 
7. Baars MJ, Scherpbier AJ, Schuwirth LW, et al. Deficient knowledge of genetics relevant for daily practice among medical students nearing graduation. Genet Med 2005;7:295-301.

8. Houwink EJ, van Luijk SJ, Henneman L, van der Vleuten C, Jan Dinant G, Cornel MC. Genetic educational needs and the role of genetics in primary care: a focus group study with multiple perspectives. BMC Fam Pract 2011;12:5.

9. Rinke ML, Mikat-Stevens N, Saul R, Driscoll A, Healy J, Tarini BA. Genetic services and attitudes in primary care pediatrics. Am J Med Genet A 2014;164A: 449-455.

10. Selkirk CG, Weissman SM, Anderson A, Hulick PJ. Physicians' preparedness for integration of genomic and pharmacogenetic testing into practice within a major healthcare system. Genet Test Mol Biomarkers 2013;17:219-225.

11. Ginsburg GS. Genomic medicine: 'grand challenges' in the translation of genomics to human health. Eur J Hum Genet 2008;16:873-874.

12. Powell KP, Cogswell WA, Christianson CA, et al. Primary care physicians' awareness, experience and opinions of direct-to-consumer genetic testing. $J$ Genet Couns 2012;21:113-126.

13. Haga $S B$, Burke W, Ginsburg GS, Mills R, Agans R. Primary care physicians' knowledge of and experience with pharmacogenetic testing. Clin Genet 2012;82:388-394.

14. Burke W, Emery J. Genetics education for primary-care providers. Nat Rev Genet 2002;3:561-566.

15. Greendale K, Pyeritz RE. Empowering primary care health professionals in medical genetics: how soon? How fast? How far? Am J Med Genet 2001;106:223-232.

16. Telner DE, Carroll JC, Talbot Y. Genetics education in medical school: a qualitative study exploring educational experiences and needs. Med Teach 2008;30:192-198.

17. Nelson EA, McGuire AL. The need for medical education reform: genomics and the changing nature of health information. Genome Med 2010;2:18.

18. Burke S, Stone A, Bedward J, Thomas H, Farndon P. A "neglected part of the curriculum" or "of limited use" ? Views on genetics training by nongenetics medical trainees and implications for delivery. Genet Med 2006;8: 109-115.

19. Bean L, Fridovich-Keil J, Hegde M, Rudd MK, Garber KB. The virtual diagnostic laboratory: a new way of teaching undergraduate medical students about genetic testing. Genet Med 2011;13:973-977.

20. Dasgupta S. Cultural competency in the medical genetics classroom: a case study for a diverse learning community. Med Sci Educ 2013;23:233-243.

21. Waggoner DJ, Martin CL. Integration of internet-based genetic databases into the medical school pre-clinical and clinical curriculum. Genet Med 2006;8: 379-382.

22. Wiener CM, Thomas PA, Goodspeed E, Valle D, Nichols DG. "Genes to society"-the logic and process of the new curriculum for the Johns Hopkins University School of Medicine. Acad Med 2010;85:498-506.

23. Dhar SU, Alford RL, Nelson EA, Potocki L. Enhancing exposure to genetics and genomics through an innovative medical school curriculum. Genet Med 2012;14:163-167.
24. Korf BR. Integration of genetics into clinical teaching in medical school education. Genet Med 2002;4(suppl 6):33S-38S.

25. Sanderson SC, Linderman MD, Kasarskis A, et al. Informed decision-making among students analyzing their personal genomes on a whole genome sequencing course: a longitudinal cohort study. Genome Med 2013;5:113.

26. Walt DR, Kuhlik A, Epstein SK, et al. Lessons learned from the introduction of personalized genotyping into a medical school curriculum. Genet Med 2011;13:63-66.

27. Vernez SL, Salari K, Ormond KE, Lee SS. Personal genome testing in medical education: student experiences with genotyping in the classroom. Genome Med 2013;5:24

28. McGovern MM, Johnston M, Brown K, Zinberg R, Cohen D. Use of standardized patients in, undergraduate medical genetics education. Teach Learn Med 2006;18:203-207.

29. Childs B, Huether CA, Murphy EA. Human genetics teaching in U.S. medical schools. Am J Hum Genet 1981;33:1-10.

30. Riccardi VM, Schmickel RD. ASHG activities relative to education: human genetics as a component of medical school curricula: a report to the American society of human genetics. Am J Hum Genet 1988;42:639-643.

31. Thurston VC, Wales PS, Bell MA, Torbeck L, Brokaw JJ. The current status of medical genetics instruction in US and Canadian medical schools. Acad Med 2007:82:441-445.

32. Feero WG, Guttmacher AE, Collins FS. Genomic medicine-an updated primer. NEng/ J Med 2010;362:2001-2011.

33. Manolio TA, Chisholm RL, Ozenberger $B$, et al. Implementing genomic medicine in the clinic: the future is here. Genet Med 2013;15:258-267.

34. Albanese MA, Mejicano G, Mullan P, Kokotailo P, Gruppen L. Defining characteristics of educational competencies. Med Ed 2008;42: 248-255.

35. Frank JR, Snell LS, Cate OT, et al. Competency-based medical education: theory to practice. Med Teach 2010;32:638-645.

36. Accreditation Council for Graduate Medical Education. ACGME Common Program Requirements. Accreditation Council for Graduate Medical Education: Chicago, IL, 2013:22.

37. Salari $K$. The dawning era of personalized medicine exposes a gap in medical education. PLoS Med 2009;6:e1000138.

38. University of Miami. Miller School launches genomic medicine master's program. 29 August 2012. http://www.miami.edu/index.php/news/releases/ miller_school_launches_first-of-its_kind_genomic_medicine_masters program/. Accessed 3 September, 2014.

39. American College of Medical Genetics and Genomics. ACMG Student Interest Groups. 2014. https://www.acmg.net/ACMG/STUDENTS/ StudentInterestGroups/ACMG/About_ACMG/ACMG_Student_Interest_ Groups.aspx?hkey=75491646-ea2b-4140-9d4c-b540701a82a5. Accessed 11 June, 2014.

40. Nees A. Number of medical schools using teaching formats and average number of hours for each format by topic area. Electronic communication with Deborah W. Vaughan. Boston University School of Medicine: Boston, MA, 8 April, 2013. 